\title{
Pilot Trial of an Electronic Family Medical History in US Faith-Based Communities
}

\author{
Patricia Newcomb', Sharon Canclini', Denise Cauble ${ }^{3}$, \\ Barbara Raudonis ${ }^{3}$, and Paulette Golden'
}

\begin{abstract}
In spite of the acknowledged importance of collecting family health information, methods of collecting, organizing, and storage of pedigree data are not uniformly utilized in practice, though several electronic tools have been developed for the purpose. Using electronic tools to gather health information may empower individuals to take responsibility in managing their family health history. The purpose of this study was to describe the feasibility and outcomes of introducing small groups to the My Family Health Portrait tool in faith-based communities using faith community nurses (FCNs). This pilot project adopted a mixed methods approach to assess the potential of an educational intervention delivered by FCNs for increasing the use of electronic technologies for organizing and storing family health histories among the general public. Treatment and control groups were recruited from four faith-based communities in north Texas using a parallel-groups quasi-experimental design. Qualitative data were gleaned from field notes made by investigators interacting with FCNs and observing their teaching. A majority of respondents believed that knowing one's health history and passing it on to family and medical personnel is important. Those receiving face-to-face instruction on the electronic tool were significantly more likely to have written down family health information than the control group who received only an informational handout $\left(\chi^{2}=5.96, P=.015\right)$. Barriers to teaching about and using the electronic tool included FCNs' lack of facility with computers in the educational context and FCN and respondent mistrust of electronic storage for family health information.
\end{abstract}

\section{Keywords}

family health history, faith-based community, nurse, pedigree

\section{Background}

Many common diseases "run in families" because of shared genetic and environmental factors; therefore health care providers are expected to collect family history information and use it for risk assessment. In spite of the importance of collecting family health information, the quality of the family history is typically poor in primary care practice. ${ }^{1}$ Furthermore, the length of time devoted to discussing family history is less than 3 minutes in any kind of primary care encounter. ${ }^{2}$ Lack of time, lack of clinician appreciation of the importance of family history information, physician perceived lack of knowledge about using pedigrees for risk assessment, and lack of reimbursement for the activity are barriers to collecting family histories in primary care. ${ }^{3,4}$ To support pedigree acquisition, the Surgeon General's electronic My Family Health Portrait tool was developed for the use of laypeople. ${ }^{5}$ The tool demonstrates several of the criteria for an ideal family history tool. ${ }^{3,4}$ It is completed by the patient or family member on behalf of a patient, elicits specific patient concerns, is brief, understandable, easy to use, and is compatible with electronic clinical applications.
Analysis of data from the 2004 Health Styles Survey revealed that $96 \%$ of respondents believed family history to be important for their own health, but only $30 \%$ collected information about family health. ${ }^{6}$ Since genetic risk may soon drive the content of electronic medical records, ${ }^{7}$ effective ways of introducing the public to electronic tools for collecting family health information are needed. Faith community nurses (FCNs) may provide an ideal avenue for introducing the public, including underserved groups, to methods for collecting and storing family health information. FCNs developed from the Parish Nurse movement nurtured by Dr Granger Westberg in the 1980s. Today, Faith Community Nursing is considered a specialty practice that is fully endorsed by the American Nurses Association. ${ }^{8}$

\footnotetext{
'Texas Health Resources, Fort Worth, TX, USA

${ }^{2}$ Texas Christian University, Fort Worth, TX, USA

${ }^{3}$ University of Texas at Arlington, Arlington, TX, USA

Corresponding Author:

Patricia Newcomb, Texas Health Resources, 70I 5th Avenue, Fort

Worth, TX 76104, USA.

Email: patricianewcomb@texashealth.org
} 
Table I. Sample Characteristics of Participants Who Returned Completed Electronic Questionnaires.

\begin{tabular}{|c|c|c|c|}
\hline Characteristic & $\begin{array}{l}\text { Percentage of Total Sample } \\
\qquad(\mathrm{N}=33)\end{array}$ & $\begin{array}{l}\text { Percentage of Intervention } \\
\text { Group }(n=10)\end{array}$ & $\begin{array}{l}\text { Percentage of Control } \\
\text { Group }(n=23)\end{array}$ \\
\hline Caucasian & 97 & 100 & 96 \\
\hline Age $40-60$ years & 55 & 100 & 61 \\
\hline Female & 76 & 90 & 70 \\
\hline Married/widowed & 88 & 80 & 91 \\
\hline Adopted & 0 & 0 & 0 \\
\hline Childless & 27 & 20 & 30 \\
\hline $\begin{array}{l}\text { Aware of possible inherited diseases in the } \\
\text { family }\end{array}$ & 61 & 80 & 52 \\
\hline $\begin{array}{l}\text { Willing to store family health information in } \\
\text { personal computer }\end{array}$ & 80 & 86 & 78 \\
\hline $\begin{array}{l}\text { Willing to store family health information on } \\
\text { Internet/cloud }\end{array}$ & 30 & 57 & 21 \\
\hline
\end{tabular}

\section{Objectives}

The objectives of this project were (1) to determine feasibility of using FCNs to teach individuals about an electronic family history tool in the faith based community setting and (2) to compare use of the My Family Health Portrait tool by subjects who receive FCN instruction with those given only printed information about the tool.

\section{Methods}

This pilot project adopted a mixed methods approach to assess outcomes of an educational intervention among a population of Christian churchgoers in north Texas. To obtain quantitative data, we used a quasi-experimental design in which a treatment group was recruited from 2 churches and a control group was recruited from 2 different churches. Qualitative data were gleaned from field notes made by investigators as they observed teaching sessions and interacted with FCNs.

Treatment churches were served by FCNs and were composed of one large ( $>5000$ members) and one small $(<1000$ members) congregation. A large and a small church that did not employ FCNs were assigned to the control condition. Members of all 4 communities were Protestant, primarily Caucasian, and urban. Recruitment of adult congregants who had e-mail accounts was conducted verbally at selected small groups, such as Sunday school gatherings. The study was institutional review board approved and written consent was obtained from subjects.

\section{Intervention Congregations}

Faith community nurses delivered a fact sheet about the $M y$ Family Health Portrait tool to subjects in their churches for 2 consecutive weekends. The information sheet contained publically available information from the US Surgeon General's Family History Initiative's Web site. Two weeks after distributing the handouts, FCNs presented training in their churches. Training sessions included content on the importance of family health information, strategies for collecting health information from family members, storage of family health information, sharing the tool-generated pedigree with health care providers, and demonstration and practice using the My Family Health Portrait tool. Three months following intervention, participants received an e-mail posttest Family Health History Survey. The survey collected information regarding congregants' recall of information about the My Family Health Portrait tool, their use of the tool, and their beliefs about the value of family health information.

\section{Control Congregations}

The same informational sheet regarding the My Family Health Portrait tool that was distributed in treatment churches was disseminated in control communities for 2 consecutive weekends. The Family Health History Survey was sent to each control participant 3 months following distribution of the informational sheets. Individuals in the control group did not receive face-to-face training in use of the electronic tool.

\section{Data Analysis}

To evaluate the feasibility of delivering instruction regarding the My Family Health Portrait Tool in the faith-based community setting we report qualitative data. Investigators observed teaching sessions and compiled field notes at the end of the intervention. To compare the use of the electronic tool by intervention participants with control participants we used $\chi^{2}$ and Fisher's exact tests to calculate the significance of differences in outcomes of participants responding to the study survey 3 months following intervention.

\section{Results}

Sample characteristics are summarized in Table 1. Though biased in respect to the general population, the sample is 


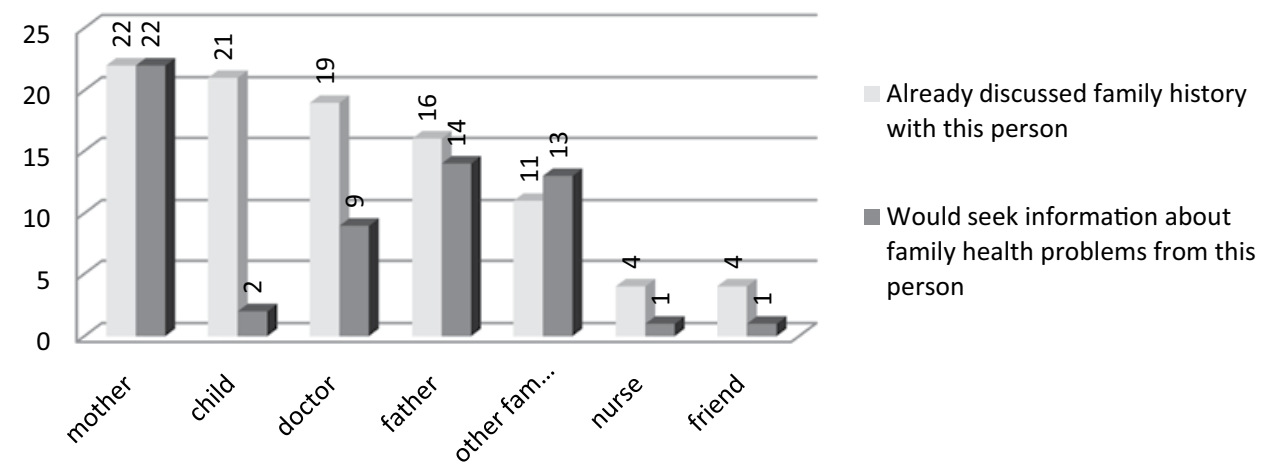

Figure I. Sources of information about family health history and family health problems.

likely representative of local nonminority Christian churchgoers. Age was not related to knowledge of potentially inheritable family illnesses $\left(\chi^{2}=6.2, P=.28\right)$. All respondents who answered the question $(\mathrm{n}=30)$ said they believed that knowing one's family history is important for one's own health and for the health of one's children. Furthermore, most respondents had discussed family health history with someone and could identify people they would seek out specifically for family health information. Figure 1 summarizes the responses to these 2 items.

Members of the face-to-face intervention group were significantly more likely to report they had heard of the $M y$ Family Health Portrait tool than members of the control group who had received written handouts about the tool $\left(\chi^{2}\right.$ $=19.86, P=.0001)$. Furthermore, treatment participants were significantly more likely to claim they had written down family health information than control participants $\left(\chi^{2}=5.96, P=.015\right)$.

The majority of subjects were willing to store family history information on their own computers, but only $30 \%$ would store family health data on the Internet. There were no significant differences between groups on these issues. Individuals unwilling to store family health information on their personal computers cited concerns about privacy, and individuals who preferred not to store family health information on the Internet were equally or more cautious about security.

Characteristics of FCNs encountered in the project were consistent with samples from other studies. ${ }^{9}$ The pool of FCNs from which we recruited was largely middle-aged or older, with a large proportion of unpaid volunteers. Although FCNs appreciated the importance of family history for medical decision making, their knowledge about genetics and pedigrees was limited. FCN attitudes regarding storage of family health information electronically was consistent with the attitudes of their congregations, and several expressed concerns about potential government snooping.

\section{Discussion}

\section{Feasibility}

Data from this sample suggest that knowing one's family health history is valued by laypeople, but individuals do not always communicate health information with other family members. This is consistent with findings from earlier studies, which found that although most respondents believed family history to be important for their own health, less than a third actually collected family health information. ${ }^{6}$ Our data support the often repeated contention that mothers are the individuals with whom we discuss our family health histories. ${ }^{10,11}$ An unexpected finding was the degree to which fathers are excluded from the process of collecting information about family health.

This pilot study demonstrated the questionable feasibility of delivering instruction regarding the My Family Health Portrait tool to faith-based communities by FCNs. Teaching congregants about the importance of family history and how to collect and store family history information seems an ideal fit for the skills and inclinations of FCNs, but the teaching and computer skills of the FCNs in this project presented barriers. The greatest challenge for FCN delivery of this particular intervention was poor computer literacy. Most FCNs had grave difficulties navigating in common search environments, such as Google, while others had difficulties becoming comfortable with the fields in the electronic tool. Most thought the tool could be helpful, but were more interested in having an "expert" deliver the training to congregants than in delivering the training themselves.

\section{Use of the My Family Health Portrait Tool}

Data from field observations suggested that participants quickly understood the purpose of the My Family Health Portrait tool and were able to navigate within it with moderate coaching. Data provided evidence that face-to-face 
teaching sessions in churches were more effective for informing congregants about the My Family Health Portrait tool than written handouts. Qualitative data also provided evidence of lack of trust of electronic storage for family health history information.

\section{Limitations}

The sample in this study is not representative of the north Texas region, but may be representative of the faith-based communities from which it was drawn. Congregations supporting faith community nurses may not represent regional population variations and attempts to deliver communitybased interventions through faith-based communities may miss large sections of the community.

\section{Conclusions}

Until FCN practice is more established and better funded, many faith communities must depend on volunteer nurses who are often retired. Many of these nurses are not technologically proficient. Training members of faith-based communities to use an electronic family history computer program may best be accomplished by FCNs who partner with experienced educators or librarians. Eventually, we hope that the value of the FCN for the health of community members will be recognized and funding for technical training, modern equipment and novel skill sets will be a requirement for this position.

\section{Acknowledgments}

The authors wish to express their gratitude to members of the faith-based communities who participated in the study. We are also grateful to Quyen Tran for her invaluable assistance with the search for literature during this project.

\section{Declaration of Conflicting Interests}

The author(s) declared no potential conflicts of interest with respect to the research, authorship, and/or publication of this article.

\section{Funding}

The author(s) received no financial support for the research, authorship, and/or publication of this article.

\section{References}

1. Medalie J, Zyzanski S, Goodwin M, Stange KC. Two physician styles of focusing on the family. J Fam Pract. 2000;49:209-215.

2. Acheson LS, Wiesner GL, Zyzanski SJ, Goodwin MA, Stange KC. Family history taking in community family practice: implications for genetic screening. Genet Med.2000;2: 180-185.

3. Rich EC, Burke W, Heaton CJ, et al. Reconsidering the family history in primary care [erratum in J Gen Intern Med. 2005;20:315]. J Gen Intern Med. 2004;19:273-280.

4. Wood ME, Stockdale A, Flynn BS. Interviews with primary care physicians regarding taking and interpreting the cancer family history. Fam Pract. 2008;25:334-340.

5. US Department of Health and Human Services. US Surgeon General's family health history initiative. 2008. http://www. hhs.gov/familyhistory. Accessed February 2, 2014.

6. Yoon PW, Scheuner MT, Gwinn M, Khoury MJ. Awareness of family health history as a risk factor for diseaseUnited States, 2004. MMWR Morb Mortal Wkly Rep. 2004;53(44):1044-1047.

7. Scheuner MT, de Vries H, Kim B, Meili RC, Olmstead SH, Teleki S. Are electronic health records ready for genomic medicine? Genet Med. 2009;11:510-517.

8. American Nurses Association. Faith Community Nursing: Scope and Standards of Practice. Silver Spring, MD: nursesbooks.org; 2005.

9. McGinnis SL, Zoske FM. The emerging role of faith community nurses in prevention and management of chronic disease. Policy Polit Nurs Pract. 2008;9:173-180.

10. Cannon EA, Schoppe-Sullivan SJ, Mangelsdorf SC, Brown GL, Sokolowski MS. Parent characteristics as antecedents of maternal gatekeeping and fathering behavior. Fam Process. 2008;47:501-519.

11. McKee MD, O'Sullivan LF, Weber CM. Perspectives on confidential care for adolescent girls. Ann Fam Med. 2006;4:519-526.

\section{Author Biographies}

Patricia Newcomb, PhD, RN, CPNP, is a nurse scientist with Texas Health Resources, a faith-based, non-profit health system. Dr. Newcomb's researc $h$ includes investigations of ways family health information is transmitted in families.

Sharon Canclini, MSN, RN, is lead faculty for the Public/community Health courses at the Harris College of Nursing, Texas Christian University. She serves the community as a volunteer for American Red Cross and as a Faith Community Nurse

Denise Cauble, BSN, $\mathrm{PhD}(\mathrm{c}), \mathrm{RN}, \mathrm{CWOCN}$, is a member of The University of Texas at Arlington College of Nursing faculty. She teaches in the undergraduate program and maintains clinical practice in community health nursing.

Barbara Raudonis, $\mathrm{PhD}$, RN, FNGNA, FPCN, is a member of The University of Texas at Arlington College of Nursing faculty. Her research includes investigations of the importance of family health history in palliative care.

Paulette Golden, MS, BSN, RN, is currently the Trauma Outreach coordinator at Texas Health Resources, Harris Methodist Hospital and a faith community nurse. Ms. Golden developed and coordinated the Faith Community Nursing program at one of the largest Texas Health Resources hospitals for twelve years. 